\title{
ESTUDO DO USO DA BIOFÍLIA EM AMBIENTES HOSPITALARES EM BELÉM - PA
}

\section{STUDY OF THE USE OF BIOPHILIA IN HOSPITAL ENVIRONMENTS IN BELEM - PA}

\author{
STEPHANIE VENTURA SINELSON | UFPA \\ MAGALI SANTOS MONASTERIOS MORALES, M.SC. | UFPA
}

\begin{abstract}
RESUMO
Um ambiente hospitalar que trata da saúde humana e funciona $24 \mathrm{~h}$ precisa de uma edificação eficiente que não siga apenas normas construtivas, mas seja humanizada de tal forma que possa impactar positivamente pacientes, e principalmente, funcionários e profissionais da saúde, levando em consideração o seu tempo de permanência maior no prédio. Pensando nesse impacto, o presente artigo traz um estudo de aplicação da biofilia, sobre a qual falaremos em detalhes mais adiante, como princípio de melhoria entre a relação ambiente natural $\mathrm{X}$ ambiente construído, considerando ambientes internos como sala de descompressão, consultório, apartamento do paciente, enfermaria e circulações no hospital Adventista em Belém do Pará. A investigação proposta é de caráter qualitativo, visando averiguar o quanto recursos da Biofilia podem contribuir na humanização de áreas importantes do prédio, principalmente áreas fechadas de uso ininterrupto, auxiliando na diminuição ao estresse normal de edifícios como este, e assim proporcionando maior conforto, produtividade e bem estar.
\end{abstract}

PALAVRAS CHAVE: Design biofílico; Espaços verde; Conforto ambiental

\begin{abstract}
A hospital environment that deals with human health and works around the clock needs an efficient building that not only follows constructive norms, but is humanized in such a way that it can positively impact patients, and mainly, employees and health professionals, taking into account their time longer stay in the building. Thinking about this impact, this article brings a study of the application of biophilia, which we will talk about in detail later, as a principle of improvement between the relationship between natural and built environment, considering internal environments such as decompression room, doctor's office, patient's apartment, infirmary and circulation at the Adventist Hospital in Belém do Pará. The proposed investigation is of a qualitative character, aiming to find out how much Biophilia resources can contribute to the humanization of important areas of the building, mainly closed areas of uninterrupted use, helping to reduce the normal stress of buildings like this, and thus providing greater comfort, productivity and well being.
\end{abstract}

KEY WORDS: Biophilic design; Green spaces; Environmental comfort 


\section{INTRODUÇÃO}

O design biofílico surge da ideia que $99 \%$ do desenvolvimento biológico do ser humano é diretamente ligado as forças da natureza, como luz, água, plantas, e não das fontes artificiais e tecnologias. Essa aproximação com o natural promove uma melhoria considerável no conforto ambiental e psicológico dos usuários, já que existe constatação de que os elementos da natureza causam reações positivas segundo a biofilia (BONI, 2018).

O contato com a natureza significa mais do que ter ar puro e um momento para relaxar a mente, ele é também uma necessidade do nosso DNA. Durante milhares de anos, o ser humano habitou as matas e o nosso organismo é moldado para esse convívio. Estar longe do verde é provocar um stress constante ao nosso corpo (MIYAZAKI, 2018).

Os cientistas comprovaram que a imersão na natureza ajuda a prevenir doenças e detém ação terapêutica. Um exemplo disso é a terapia banho de floresta (Shinrin-yoku), que segundo Miyazaki é uma das formas mais simples para se libertar do stress e evitar doenças relacionadas a tensão das grandes cidades. É um tratamento natural que consiste no ato de tirar maior proveito da exposição a natureza e pode ser realizado em qualquer momento da vida.

Atualmente, ao pensar-se na arquitetura de um edifício deve-se ter total consciência de que cada detalhe terá um grande impacto na vida dos usuários daquele espaço, considerando-se que estes podem passar até $90 \%$ do seu dia em ambientes internos, as decisões de ventilação, insolação, layout, e fluxo interno podem influenciar diretamente na saúde e bem estar do usuário (BONI, 2018).

Em se tratando de ambientes hospitalares, isso se manifesta em uma busca crescente por ambientes mais humanizados. Neste sentido, ao delimitar os profissionais de saúde ao objeto de estudo, deve-se levar em consideração que estes encontram-se em sua maior parte do tempo, no interior da edificação. O que diminui consideravelmente o contato deles com os elementos da natureza externa existente ou inexistente, atribuindo assim uma importância maior para o incremento dos atributos biofílicos em espaços internos.

Em um edifício comercial ou de serviço, o bem-estar e a satisfação pessoal do funcionário tem consequências diretas no seu rendimento. Estudos já revelaram que usuários de ambientes fechados, com climatização artificial, apresentam altos índices de desenvolvimento de problemas de saúde como: alergias, dores de cabeça, dores de garganta, fadiga em geral, etc., com comprovação de que estavam diretamente ligados as condições ambientais do local (TEIXEIRA et al, 2005).
A pouca presença ou inexistência de áreas verdes em hospitais vem sendo um problema que está relacionado às leis urbanísticas locais, pois está intrinsicamente ligada a uma problemática ambiental do não-uso ou uso insuficiente de áreas permeáveis e espaços de descompressão. Embora esse assunto não seja objeto principal do estudo exposto, uma reflexão acerca do déficit de porcentagem permeável permitida deve ser considerada. Afim de responder essa questão, procura-se elucidar o uso das áreas verdes existentes e os impactos positivos provocados nos usuários.

Diante das evidências positivas da biofilia atestada por diferentes pesquisas, o presente estudo investiga qualitativamente a aceitabilidade do uso da biofilia em ambientes internos, por profissionais de tempo integral no Hospital Adventista na cidade de Belém - PA. Através de questionário, buscam-se possíveis soluções na biofilia para aproximar os usuários a natureza com o objetivo de melhorar seu rendimento e bem-estar.

\section{REVISÃO BIBLIOGRÁFICA}

Neste estudo aborda-se três áreas de conhecimento para a pesquisa: experiências e atributos do design biofílico, como estratégias para aplicação de projetos mais sustentáveis e saudáveis. Hospitais humanizados, que permitem aos usuários um tratamento mais humano. E por fim, a importância das áreas verdes na legislação urbanística de Belém em edificações hospitalares.

\subsection{Experiências e atributos do design biofílico} O design biofílico possibilita encontrar soluções para as deficiências das edificações contemporâneas, estabelecendo novos meios que permitam a satisfação da experiência junto à natureza, no contexto da construção. O objetivo é a criação de "habitats" agradáveis ao ser humano, ambientes que qualifiquem a saúde e o bem-estar (CALABRESE; KELLERT, 2017).

Segundo Joye (2007), a imitação dos elementos naturais na arquitetura e a concepção de ambientes que promovam o contato direto com a natureza pode ter efeitos positivos no homem e à redução do estresse. De acordo com o autor, os arquitetos podem usar a natureza como fonte de inspiração, através de propostas práticas, desde imitações dos elementos naturais, uso de elementos naturais (como plantas), uso de geometria fractal da natureza na arquitetura. Porém, observando as edificações atuais, as oportunidades de contato com esses elementos são reduzidas na vida urbana e ainda estão distantes da prática.

De acordo com as estratégias para aplicação do design biofílico, Calabrese e Kellert (2017) pontuam 24 atributos objetivos e os dividem em três categorias: a experiência direta 
com a natureza; a experiência indireta com a natureza; e a experiência do espaço/lugar. Essa divisão permite uma meIhor compreensão e incorporação de diversas estratégias no ambiente construído, como está descrito a seguir:

- A experiência direta com a natureza se refere ao contato direto com elementos, tais como luz e ar natural, plantas, animais, água, fogo, áreas abertas (clima) e paisagens naturais;

- A experiência indireta com a natureza diz respeito ao contato com representações ou imagens de referência, como fotos, quadros, materiais naturais e ornamentação inspirada em formas da natureza. Também fazem parte da experiência indireta: o uso de cores naturais, as simulações de luz e ar natural, a riqueza de informações, as geometrias naturais e a biomimética;

- A última divisão aborda características espaciais próprias do mundo natural, como espaços que estimulam a aventura ou refúgio, a complexidade organizada, fluxos e circulações, integração das partes com o todo, espaços de transição, além de vínculos culturais e ecológicos com o local.

\subsection{Hospitais humanizados}

Assim como todos os edifícios, a arquitetura hospitalar teve evolução ao longo dos tempos. No princípio, espaços hospitalares eram ambientes insalubres sem ventilação e iluminação precária. A partir de meados do século $X X$, o espaço hospitalar foi finalmente abordado de forma diferente, tornando-se um promotor de saúde e contribuindo com a cura dos pacientes (Lukiantchuki; Ramos, 2015).

Segundo Lukiantchuki e Ramos (2015), essa mudança foi definida com os hospitais humanizados que passaram a dar atenção a 3 pontos importantes:

- A humanização dos espaços através do uso de artes visuais;

- A importância do uso dos condicionantes naturais, dentre eles a ventilação e a iluminação natural;

- A contribuição do uso de vegetações para o bem-estar ambiental.

Estes pontos devem ser considerados, pois influenciam diretamente na cura física e psicológica do paciente e na saúde do profissional de saúde, que lida diariamente com pessoas doentes e cujo bem-estar está diretamente ligado à sua maneira de trabalhar. Neste aspecto, a humanização em hospitais é necessária para oferecer um bom atendimento aos pacientes e transmitir confiança para a família, independentemente das tecnologias oferecidas pelo mesmo.

Segundo Dobbert (2010):

O simples fato de poderem observar uma paisagem provida de vegetação com cores e outros atrativos é o suficiente para provocar bem-estar considerável em quem a vivencia.
Logo, aberturas com visibilidade para área externa auxiliam o usuário na sua saúde psicológica, dando assim, uma importância maior à renovação do ar e a promoção de iluminação natural.

Para os funcionários que não dispõem de um contato direto com esses espaços, é possível utilizar-se de estratégias que trazem a natureza para a área interna, através de ambientes pensados com base no design biofílico, que incorporem elementos naturais, cores, layout, ventilação e iluminação para a promoção do bem-estar psicológico nos ambientes.

\subsection{Importância das áreas verdes na legislação urbanística de Belém para edificações hospitalares}

Com o desenvolvimento das cidades houve um grande processo de condensação social e espacial, onde não houve um planejamento estruturado, dando origem a modelos urbanos não sustentáveis. Um modelo mais sustentável leva em consideração ter uma infraestrutura verde que, segundo Coutts, é um espaço verde conectado com o objetivo de conservar os valores naturais de um ecossistema e trazer benefícios à população (COUTTS; HAHN, 2015).

Neste contexto, além de atribuírem melhorias ao meio ambiente para maior equilíbrio ambiental, as áreas verdes também contribuem para o desenvolvimento social e trazem benefícios ao bem-estar, a saúde física e psíquica da população, ao proporcionarem condições de aproximação do homem com o meio natural.

Ter contato com áreas arborizadas contribui para a redução de estresse, melhoria do desenvolvimento cognitivo, aumento de atividade física, redução de doenças infecciosas, aumento da interação social, redução de ruídos, regulação térmica e produção de alimentos, além de se tornar um filtro de poluentes atmosféricos (LOURENÇO et al, 2016).

$\mathrm{Na}$ cidade de Belém do Pará, o Plano Diretor LEI No 8.655, de 30 de julho de 2008, junto com sua Lei Complementar de Controle Urbanístico (LCCU) regem o planejamento urbano da cidade. O nível de permeabilidade que cada espaço deve conter, através da taxa de permeabilidade, gira em função da área construída e do modelo urbanístico a ser adotado.

Segundo o Art. 12 da LCCU, que define as políticas setoriais a serem adotadas, incentivar o estabelecimento de permeabilidade no lote e pavimentação porosa de forma a facilitar a passagem da água e a retirada do calor pelo fenômeno da evaporação são medidas de grande importância. Esta mesma lei define a taxa de permeabilidade, dependendo da categoria de uso e da área da edificação. No caso de comércios e serviços, a categoria que se encaixa ao objeto de estudo exposto é uma taxa de $10 \%$ do total do lote. 
Considerando-se uma área de $100 \mathrm{~m}^{2}$, apenas $10 \mathrm{~m}^{2}$ devem, obrigatoriamente, ter permeabilidade. Embora o espaço possa possuir uma área maior, quem estipulará este valor é o empreendedor e o cliente responsável pela construção. Isso contribui para a isenção no processo de permeabilidade do solo, que tendem a reduzir os fenômenos negativos causados pela falta de uma boa infraestrutura e o alto índice de pluviosidade. Usualmente, há uma despreocupação com o meio ambiente e prefere-se utilizar o máximo de área construída com o intuito de ter maior lucro.

É importante que seja feita uma reflexão acerca de um aumento da taxa no Plano Diretor, como muitos outros já fizeram no Brasil, de forma a ajudar no desenvolvimento da infraestrutura do espaço. Por exemplo, a taxa no Rio de Janeiro é de 15\%, em Curitiba é de 25\%, e em São Paulo ela varia entre $15 \%$ a $25 \%$, dependendo do lote. Esta iniciativa de uma maior taxa é muito importante, pois a existência de locais com uma boa permeabilidade cria maiores condições de aproximação do homem com o meio natural.

\section{METODOLOGIA}

Para o desenvolvimento deste trabalho, a estratégia da pesquisa é apontada como descritiva e exploratória, uma vez que esse tipo de pesquisa busca aprimorar ideias e a descoberta de experiências, com o objetivo de um maior entendimento do problema estudado. No que se refere à abordagem, foi adotado o caráter qualitativo, haja vista que ele considera a percepção dos entrevistados com o problema abordado (GIL, 2008).

Além da revisão bibliográfica, a pesquisa básica estratégica viabiliza, por meio de simulações, a aplicação das experiências e atributos biofílicos como meio para atingir impactos positivos e maior entendimento do ambiente construído com base nas necessidades dos usuários (CALABRESE; KELLERT, 2017).

As etapas consistem na delimitação do público-alvo que irão responder ao questionário, seguido do levantamento dos ambientes do hospital onde serão elaboradas as simulações e posterior aplicação do questionário.

\subsection{Delimitação do público-alvo}

A delimitação do público-alvo ocorreu onde se encontram a maior quantidade de profissionais na área da saúde: médicos e enfermeiros (técnicos e auxiliares), que trabalham em horário fixo integral, visto que há uma maior tendência de permanência destas pessoas em ambientes hospitalares.

\subsection{Levantamento dos ambientes escolhidos}

Para melhor aplicação dos atributos da biofilia nos ambientes, escolheu-se espaços de maior permanência dos profissionais. O levantamento fotográfico foi realizado no dia 07 de fevereiro de 2020, no Hospital Adventista de Belém (HAB). A escolha e registros foram essenciais para verificar o atual estado de cada ambiente, com o intuito de utilizá-las para a elaboração das simulações. Os ambientes escolhidos são respectivamente: duas circulações no bloco de internamento, um apartamento do paciente, um consultório e uma enfermaria.

\subsection{Elaboração do questionário}

Elaborou-se um questionário com o intuito de identificar as percepções e impressões em relação aos espaços frequentados pelos usuários.

Na fase de elaboração, as perguntas foram categorizadas em primeiro momento quanto ao tempo de trabalho do corpo de trabalhadores com ênfase no bem-estar e saúde. Em segundo momento, quanto ao uso dos espaços verdes externo, para finalmente investigar as impressões de aceitabilidade ao uso da biofilia por meio das simulações. Para isso, a presença de fotos ao lado foi vinculada as simulações que permitissem ao participante recordar os elementos e ambientes da edificação existente.

Dentre as alternativas para os participantes escolherem foram selecionados dois tipos de respostas: as dicotômicas "sim/não" e as únicas, nas quais apenas um tipo pode ser escolhido. O questionário também se propunha a indicar qual a relevância das impressões nas simulações, ou seja, aqueles que são mais apreciados pelos usuários. Considera-se "Ótimo" para maior aceitabilidade, "Bom" e "Regular" para média aceitabilidade e "Ruim" para menor aceitabilidade, relacionados à presença de cada atributo biofílico do ambiente construído. (Figura 01)

4. Qual sua impressão em relação a esses espaços após sofrerem essas alterações? ( ) Ótimo ( ) Bom ( ) Regular ( ) Ruim

Figura 01: Modelo Questão Fonte: autor, 2020

\section{RESULTADOS E DISCUSSÕES}

\section{1. Área construída e área de descompressão}

O Hospital Adventista de Belém (HAB) localiza-se na Avenida Almirante Barroso, 1758, no bairro do Marco em Belém/Pa. A construção sofreu várias ampliações e reformas ao longo dos anos, atualmente é composta por 4 blocos interligados, conhecidos como: edifício 
administrativo, edifício garagem, bloco de internamento e bloco de urgência e emergência. Todos os blocos são interligados entre si, formando uma planta em formato de "U”. (Figura 02)

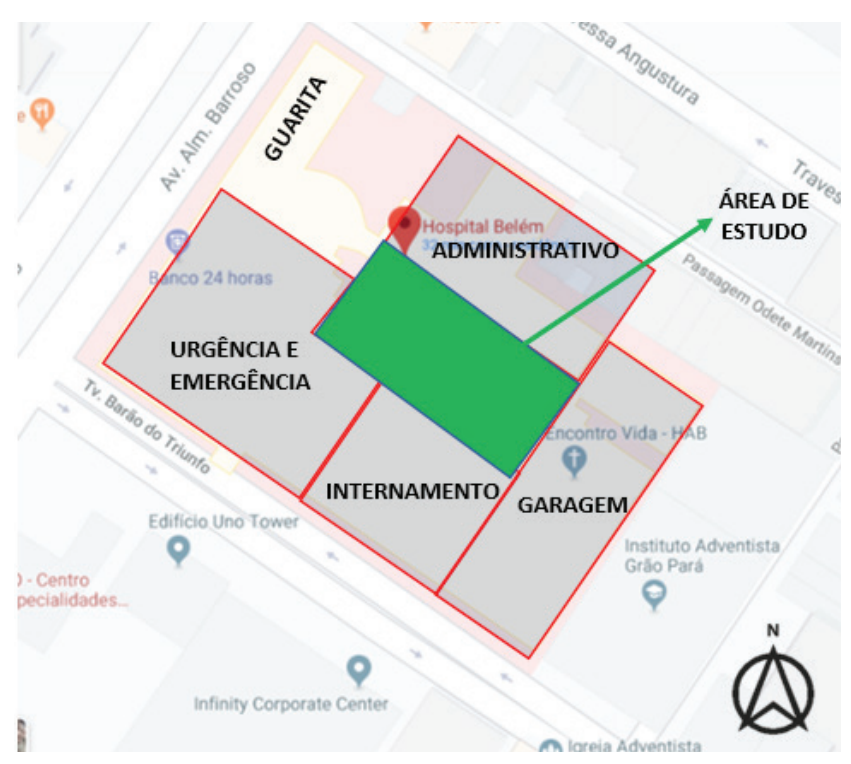

Figura 02: Planta esquemática $H A B$

Fonte: Google Maps; adaptado, 2020

Na parte central, o hospital possui $437,65 \mathrm{~m}^{2}$ de área de verde em um total de $1.557,37 \mathrm{~m}^{2}$ de área permeável. A escolha se deu justamente por ser uma das poucas instituições de saúde na cidade com presença significante de espaço externo para convivência. Isso evidencia a importância e o impacto positivo que as áreas de descompressão proporcionam ao possibilitar a criação de locais agradáveis para a coletividade, onde as pessoas possam se reunir assim como se isolar para relaxar do estresse cotidiano. (Figura 03)

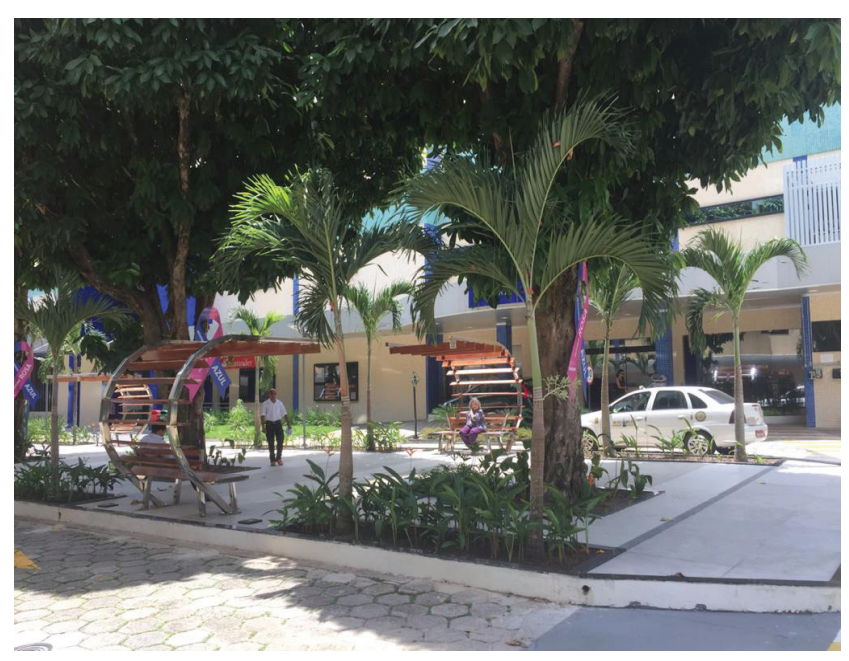

Figura 03: Área de convívio externa.

Fonte: autor, 2020
No entanto, investiga-se que a maioria dos profissionais de saúde trabalham por tempo integral e encontram-se boa parte das horas de seus turnos em ambientes internos, ou seja, em $39.728 \mathrm{~m}^{2}$ de área construída. Para atender estas pessoas, a criação de locais de descanso se torna cada vez mais importante. Atualmente, já é discutida a elaboração de leis no Estado de São Paulo para legitimar a criação desses espaços em hospitais públicos e privados para o usufruto de enfermeiros, técnicos e auxiliares de enfermagem.

Ainda nesse contexto, (PETENUZZO, 2020) com base no espaço compartilhado utilizado diariamente para aliviar o estresse em meio à pandemia de Covid-19 no Estado de Porto Alegre, coletivos de arquitetos se sensibilizaram e colaboraram com projetos de salas de descompressão para servir de local de repouso a estes profissionais. Segundo a Arquiteta Daniela Giffoni (2020):

Esse ambiente é um carinho do Hospital de Clínicas para o profissional da saúde, é um abraço para essas pessoas que, em alguns momentos, nem para casa conseguirão voltar.

\subsection{Aplicação do questionário}

As entrevistas foram realizadas no período de 22 até 24 de abril de 2020, de forma presencial e virtual entre médicos e enfermeiros que frequentam a instituição. A abordagem direta não ocorreu com os participantes em virtude das exigências de isolamento. Em vista disso, os formulários foram dispostos no balcão de enfermaria em espaços fechados e alguns entregues nos consultórios para motivar a participação na pesquisa. A plataforma Google Forms foi utilizada para viabilizar as entrevistas à distância.

Todos os dados individuais foram respostas escolhidas pelos entrevistados, coletadas e armazenadas no programa Microsoft Office Excel, e em seguida apresentadas em gráficos para análise qualitativa. A pesquisa foi realizada onde a amostra de pessoas entrevistadas se deteve a 42 pessoas, para uma margem de erro no valor de $9 \%$.

A primeira aproximação foi direcionada quanto ao período de trabalho, o que possibilitou dividi-los em dois grupos: os de meio período 33,3\% (14 profissionais) e os integrais $66,7 \%$ (28 profissionais), em um total de 42 profissionais. (Gráfico 01) 


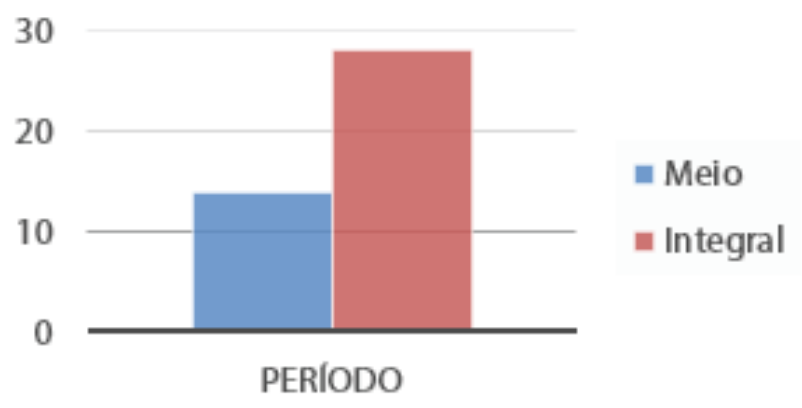

Gráfico 01: Período de trabalho Fonte: autor, 2020

Para este estudo, considerando-se o tempo de permanência, delimitou-se ao grupo de trabalhadores de tempo integral.

\subsection{Quanto ao tempo de permanência e bem estar no ambiente de trabalho}

As entrevistas realizadas demonstraram que uma maioria de $46,4 \%$ dos entrevistados trabalha mais de 8 horas por dia e $42,9 \%$ trabalham somente 8 horas por dia no estabelecimento, ou seja, um valor equivalente a $89,3 \%$. Para uma minoria que respondeu 6 horas de trabalho ou menos, isso ocorre pela grande rotatividade dentro do edifício, pelo deslocamento desses profissionais para outros hospitais, clínicas ou laboratórios, como principal razão para esse valor de 10,7\%. (Gráfico 02)

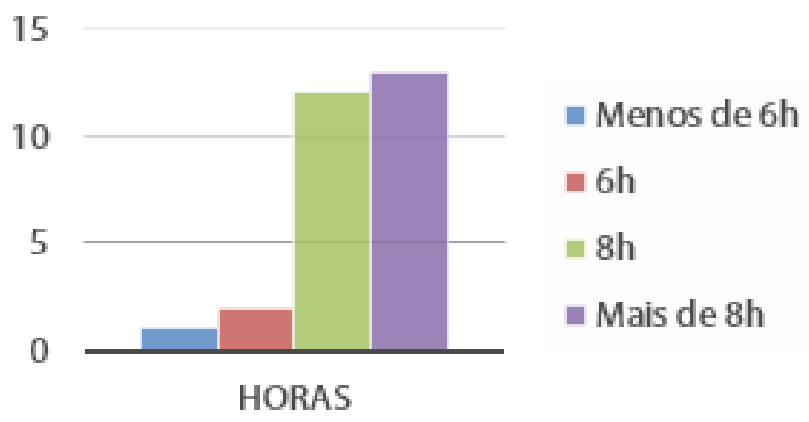

Gráfico 02: Horas de trabalho

Fonte: autor, 2020

Dessas horas, o tempo de permanência em ambientes fechados dos interrogados é de mais de 2 horas, com $96,4 \%$ e igual a 2 horas com 3,6\%. Quanto aos ambientes abertos, houve uma maior variação de respostas, 39,3\% permanecem menos de 1 hora e 35,7\% não possuem nenhum horário para visitar esses espaços. Isso demonstra que embora esses profissionais não tenham tempo, ainda assim, acomodam-se alguns minutos para estarem em ambiências agradáveis durante o seu serviço. (Gráfico 03)

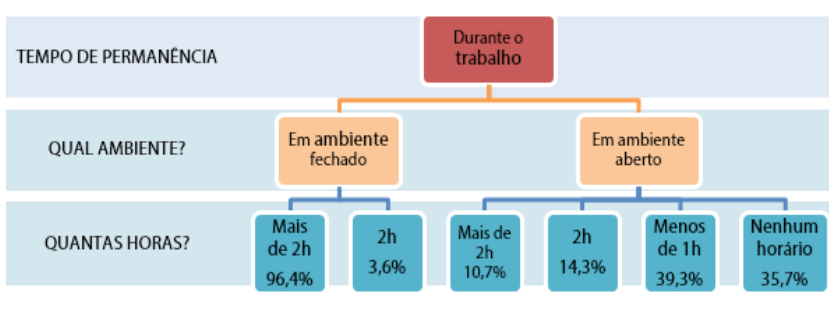

Gráfico 03: Tempo de permanência

Fonte: autor, 2020

Dentre os ambientes internos de uso ininterrupto estão: as circulações, o apartamento do paciente, o consultório, e a enfermaria. Os profissionais responderam que permanecem mais tempo no consultório, $82,1 \%$ e na enfermaria, 17,9\%. (Gráfico 04)

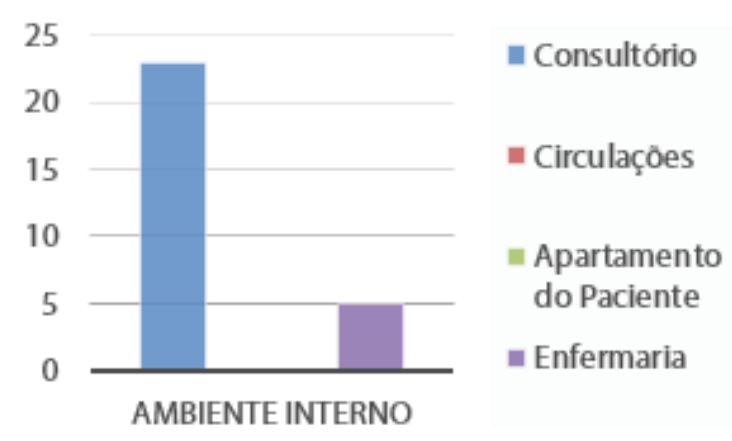

Gráfico 04: Maior permanência Fonte: autor, 2020

Correlacionado a isso, questionou-se a relação da presença de vegetação ao local de trabalho, sendo que $82,1 \%$ dos profissionais não presenciaram e $17,9 \%$ presenciaram. Portanto, grande parte dos ambientes não possuem plantas, estes valores evidenciam uma realidade muito comum em muitos hospitais. (Gráfico 05)

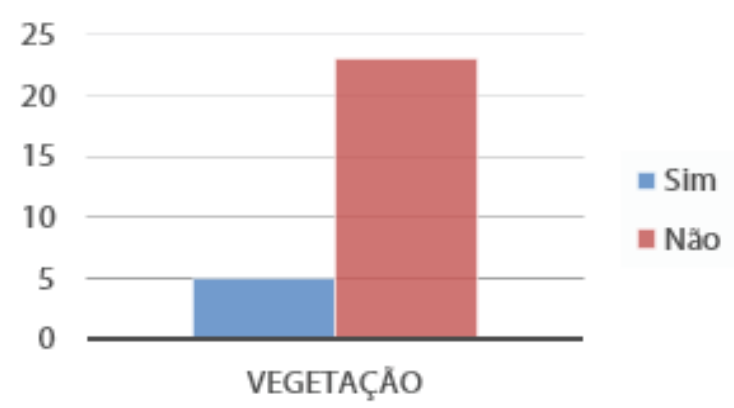

Gráfico 05: Presença de vegetação

Fonte: autor, 2020

Em relação ao bem estar desses profissionais no local de trabalho, aspectos psicológicos são importantes devido a sua correlação com o nível de produtividade e estresse para o bom desempenho da profissão. Foi considerado 
como ótimo por 3,6\%, bom por $28,6 \%$, regular por $46,4 \%$, e ruim por $21,4 \%$ dos funcionários que sofrem com estresse, mesmo que seja mediano. Já para a produtividade considera-se como ótimo por $10,7 \%$, bom por $60,7 \%$, regular por $25 \%$, e ruim por $3,6 \%$ dos funcionários. (Gráfico 06 )

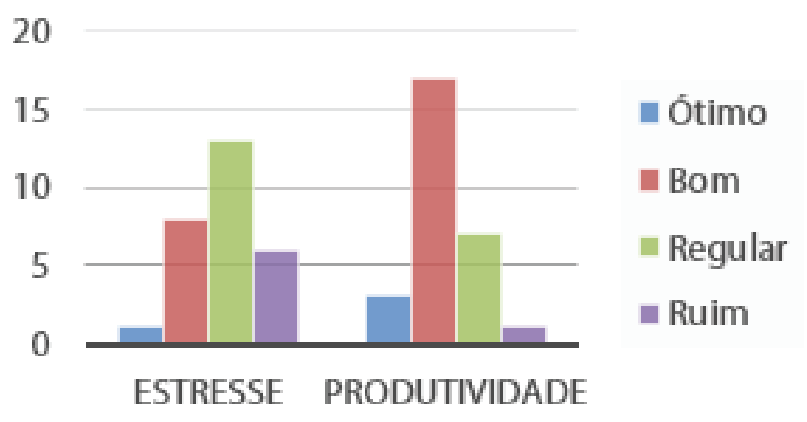

Gráfico 06: Produtividade e Estresse Fonte: autor, 2020

Para reduzir o estresse entre enfermeiros e médicos, existem exemplos de intervenções que visam especificamente a redução do estresse com base no espaço compartilhado que eles usam diariamente. Por exemplo, o acréscimo de pinturas de paisagens nas paredes da enfermaria e instalação de um pequeno jardim e assentos no pátio interior adjacente.

\subsection{Quanto aos espaços verdes}

Quanto ao contato deles com os elementos da natureza por meio dos espaços verdes existentes, fez-se as seguintes perguntas:

1. Nas horas vagas você frequenta os espaços verdes?

2. Eles estão em um local de fácil acesso?

3. Você acredita possuir área verde suficiente no local?

Com base nas respostas dicotômicas adquiridas quanto ao uso dos espaços verdes existentes nas horas vagas, o espaço é frequentado por $39,3 \%$ dos profissionais, e $60,7 \%$ responderam que não frequentam. Estes espaços foram descritos como de fácil acesso por 57,1\%, contra 42,9\% que descreveram não ser. Uma porcentagem de $71,4 \%$ dos profissionais acredita não possuir espaços verdes suficiente no local, enquanto $28,6 \%$ acreditam que a quantidade existente é suficiente. (Gráfico 07)

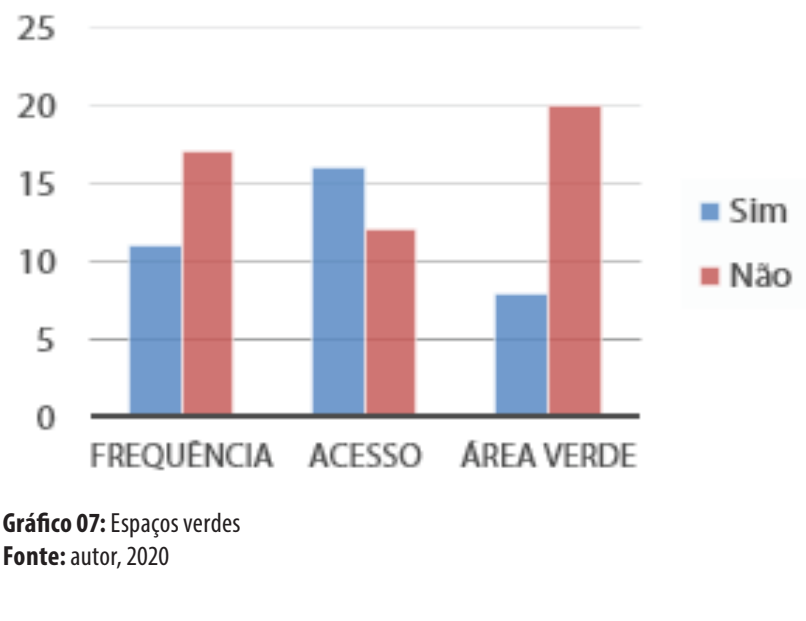

Os resultados apontam que por mais que estes espaços sejam acessíveis e visíveis a todos, a maioria dos entrevistados não tem o hábito ou o tempo necessário para frequentar os espaços verdes. Sua relação com os elementos da natureza se restringe ao deslocamento até a edificação e visão do espaço como simples elemento paisagístico.

Não obstante, ficou evidente o fácil acesso a área de convivência, em função da sua localização estratégica ao centro do terreno. Portanto, a maioria dos interrogados respondeu que sim no que se refere ao fácil acesso desses espaços e que não acreditam possuir área verde suficiente.

\subsection{Quanto ao uso da biofilia}

Perguntas relacionadas ao tema da biofilia se fizeram essenciais na aplicação de soluções nos recintos, assim como uma maior percepção dos usuários. Segundo Edward Wilson, a biofilia "amor pela vida" é a necessidade que sentimos de estar em contato, interagir e nos relacionarmos com a natureza. Quanto ao conhecimento, 89,3\% dos entrevistados não sabem o que é biofilia, e somente 10,7\% afirmaram saber. (Gráfico 08)

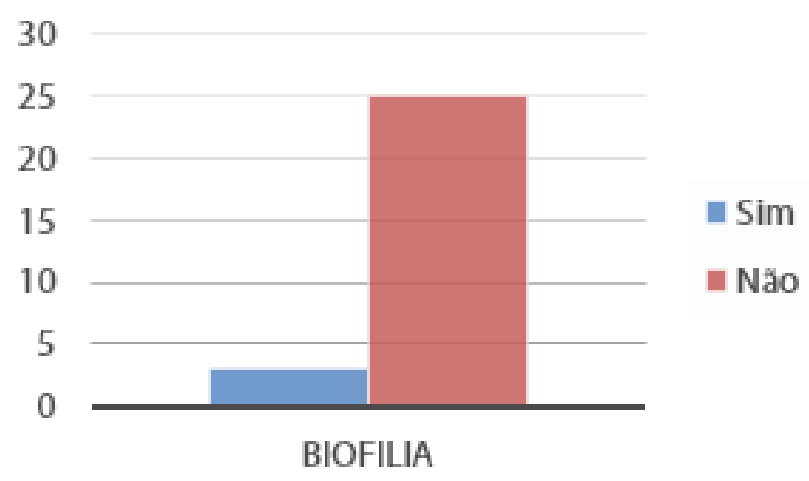

Gráfico 08: Conhecimento Fonte: autor, 2020

Há falta de atributos diretos e indiretos relacionados a natureza em ambos os espaços, o que evidencia uma 
maior necessidade desses elementos. Em espaço fechado, os atributos biofílicos que mais fazem falta são imagens da natureza 39,3\% e materiais naturais 35,7\%. (Gráfico 09)

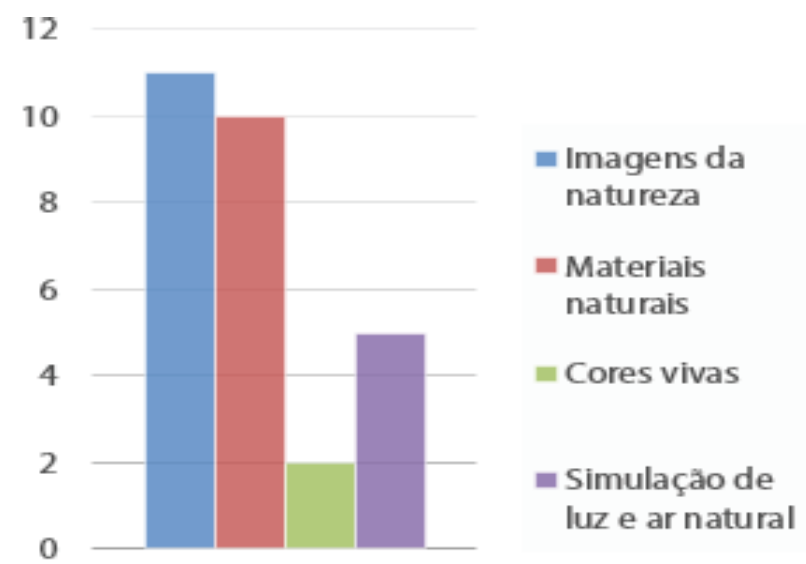

Gráfico 09: Atributos biofílicos em espaços fechado Fonte: autor, 2020

Em espaço aberto, os atributos biofílicos que mais fazem falta são vegetação 35,7\%, e paisagens 35,7\%. (Gráfico 10)

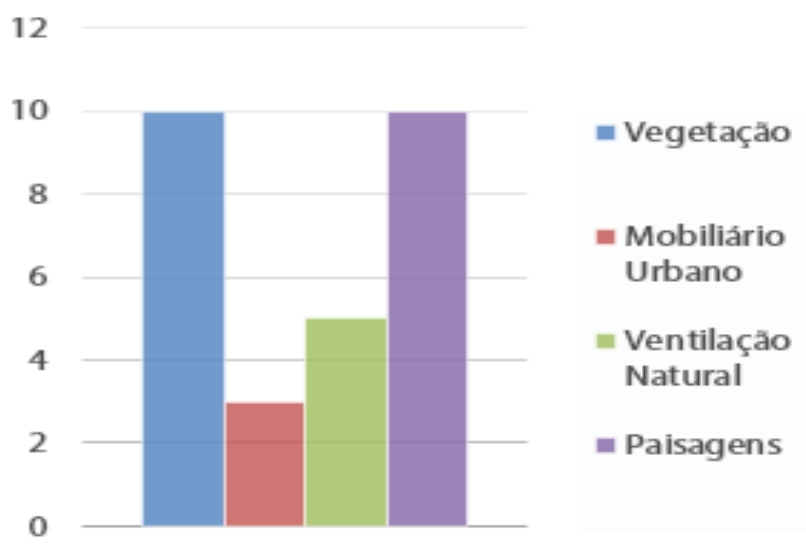

Gráfico 10: Atributos biofílicos em espaços abertos Fonte: autor, 2020

Quanto a aplicação dos atributos biofílicos, escolheram-se os espaços de maior permanência dos profissionais. Os ambientes hospitalares escolhidos são respectivamente: as circulações, o apartamento do paciente, o consultório e a enfermaria.

Vale ressaltar que pensar na biofilia de maneira mais integrada é mais fácil quando aplicada em um projeto que ainda não foi construído. Já que existe uma série de aplicações possíveis, por exemplo, quanto ao uso da iluminação de Led com cores para ambientação etc.

Nesse caso, interviu-se da melhor forma possível, pois a biofilia proporciona uma gama de opções de uso que não puderam ser exploradas em sua totalidade devido a limitação de lidar com ambientes já construídos.
As simulações foram realizadas com base nos 24 atributos objetivos, divididos em experiências direta com a natureza, experiências indiretas com a natureza e experiências do espaço/lugar, segundo os estudos de Calabrese e Kellert (2017). (Figuras 04 a 08)

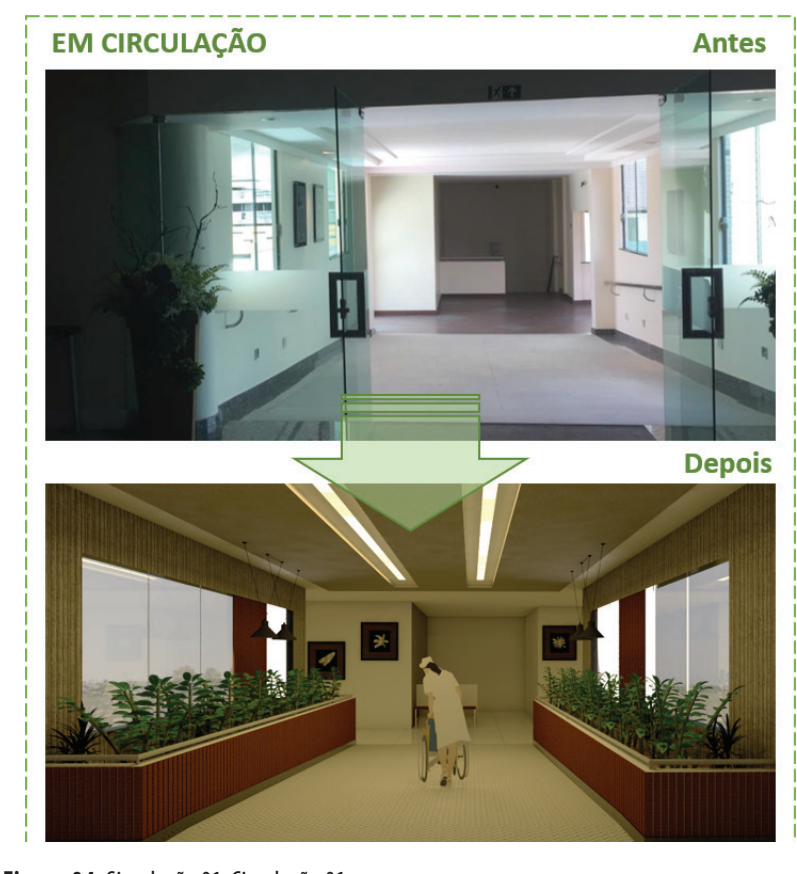

Figura 04: Simulação 01: Circulação 01

Fonte: autor, 2020

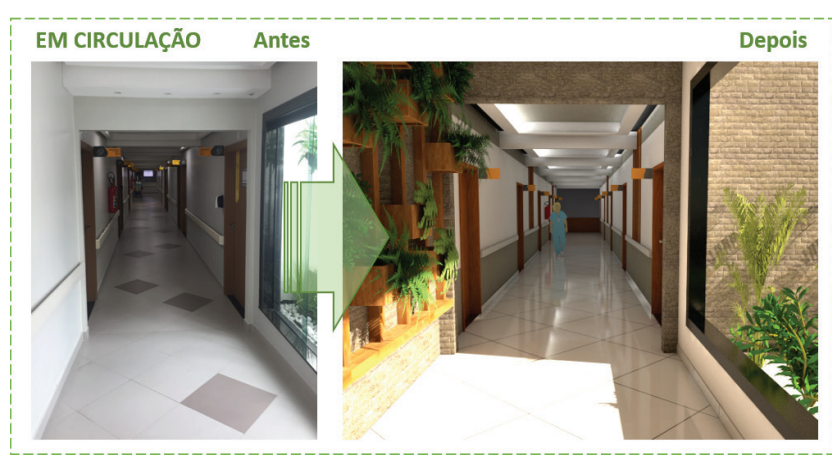

Figura 05: Simulação 02: Circulação 02

Fonte: autor, 2020

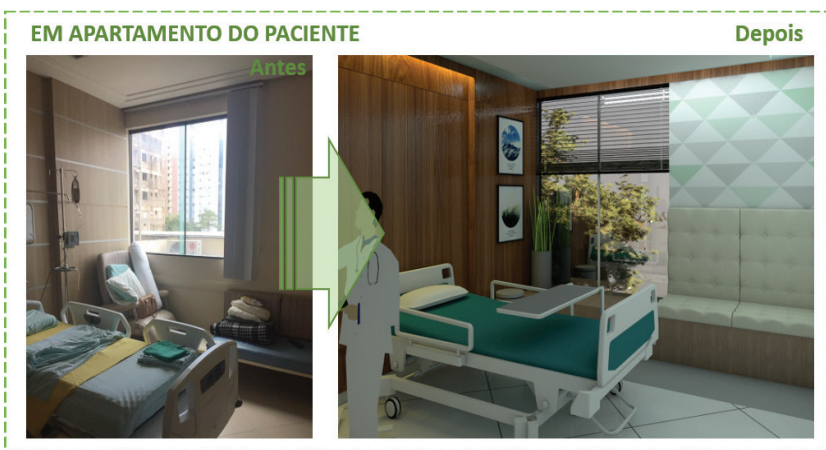

Figura 06: Simulação 03: Apartamento do paciente Fonte: autor, 2020 


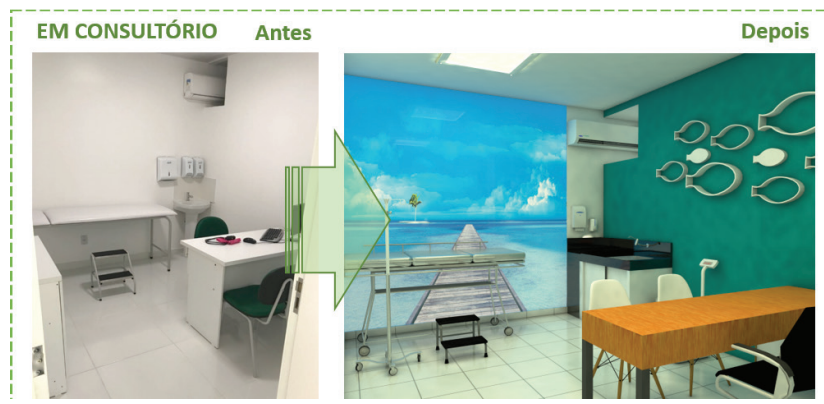

Figura 07: Simulação 04: Consultório Fonte: autor, 2020

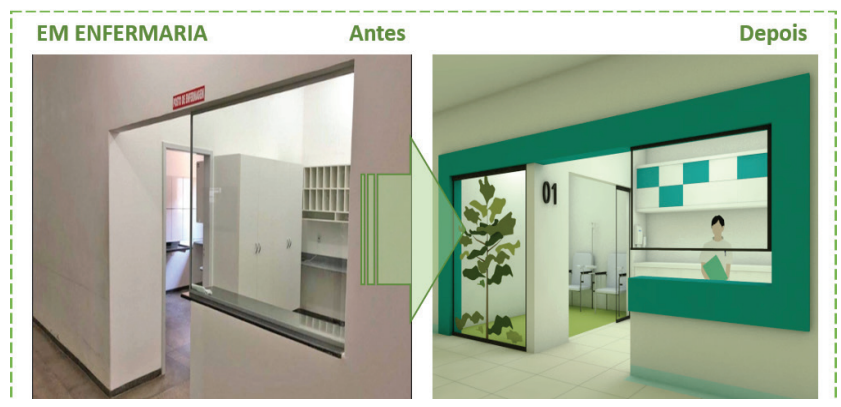

Figura 08: Simulação 05: Enfermaria

Fonte: autor, 2020

Houve uma ótima aceitação em relação a presença dos atributos que envolvem elementos naturais nos ambientes, vegetação e revestimentos naturais como madeira, pedras, bambu, etc. A presença desses elementos trouxe um impacto positivo em três das simulações que foram mais presenciadas, aonde os entrevistados consideraram como ótimo: simulação 01 com 60,7\%, simulação 02 com 67,9\% e simulação 03 com 67,9\%. (Gráfico 11)

Para os ambientes sem a presença de janelas houve menor impacto por parte dos entrevistados. O uso de cores e de imagens que remetem a natureza trouxe aceitação entre bom e regular: simulação 04 com bom 32,1\%, regular $21,4 \%$ e ruim $7,1 \%$, simulação 05 com bom $32,1 \%$ e regular $14,3 \%$. Podendo ser considerada como solução, a utilização de cores mais vivas ou pinturas com temas da natureza para tornar o ambiente de trabalho mais agradável. (Gráfico 11)

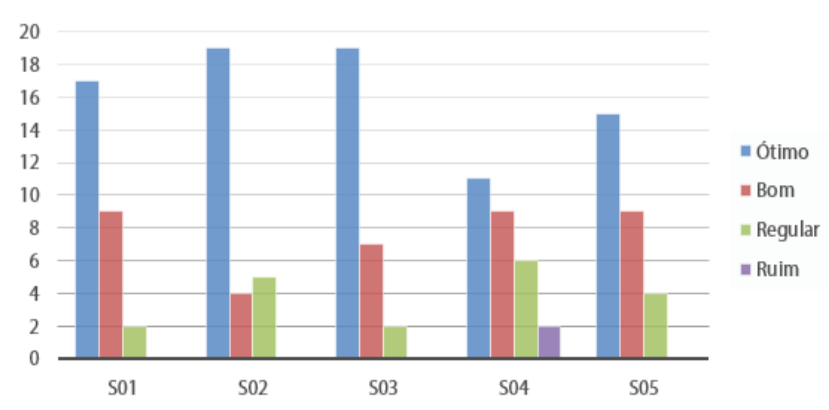

Gráfico 11: Simulações Fonte: autor, 2020
Após um maior entendimento sobre o que é a biofilia e sua importância aplicada nos recintos com as simulações, $85,7 \%$ dos entrevistados afirmaram que diminuiria seu nível de estresse e 14,3\% afirmaram que aumentaria sua produtividade. (Gráfico 12)

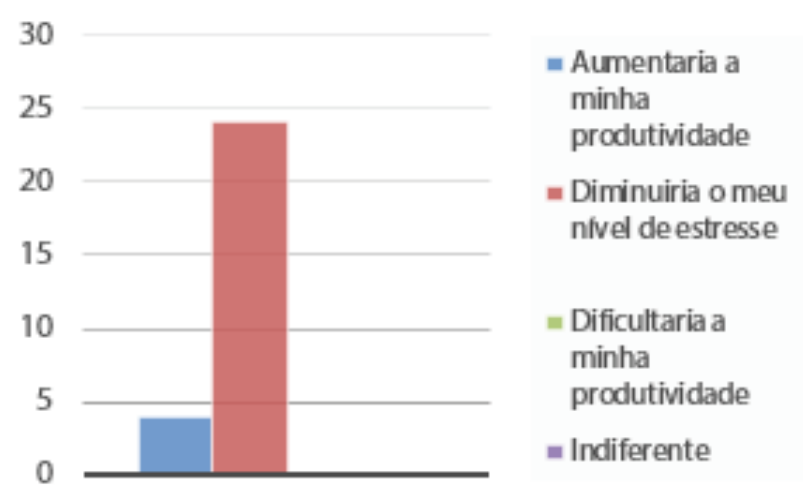

Gráfico 12: Mudanças no bem estar Fonte: autor, 2020

Por meio do questionário percebeu-se uma maior percepção vinda dos profissionais em relação a biofilia, ampliando seu olhar em relação aos espaços de trabalho, os quais não necessitam ser ambientes com cores neutras, sem vida, podendo ser adaptados e promover conforto igual ou até superior aos espaços já existentes.

O design biofílico busca uma maior integração entre o ser humano e a natureza, por meio de investimentos em que o objetivo final seja a valorização dos espaços para o bem-estar. É necessário que as pessoas percebam a importância de fazer parte de um novo conceito de habitar, por meio da aproximação do projetista e da real necessidade dos usuários. Nesse aspecto, para os arquitetos prever a aplicação da biofilia desde a concepção do projeto é de grande valia.

\section{CONSIDERAÇÕES FINAIS}

Há poucos anos, nos tornamos moradores urbanos com maior quantidade de pessoas vivendo nas cidades do que no campo. Com essa mudança, a primordialidade de se conectar e reconectar com a natureza se torna cada vez mais importante para nossa saúde e bem-estar, assim como a crença de que ela não é um luxo, mas uma necessidade.

Espera-se deste estudo que os resultados apresentados contribuam para que a biofilia seja adotada, sobretudo em prédios hospitalares, e incentive a inovação que incorpore os atributos do design biofílico para locais de trabalho saudáveis. Assim como acredita-se também na abertura de um leque de possibilidades no uso da arquitetura nos espaços, a fim de impactar positivamente a vida de pacientes, e principalmente de funcionários e profissionais da saúde. 
As soluções nas simulações decorreram por meio de alteração de cores, colocação de painéis que remetem a natureza, utilização de vegetação nos recintos de forma artificial ou natural e reaproveitamento de espaços ociosos. Diante da aplicação das simulações em uma edificação já existente, percentualmente obteve-se uma boa aceitabilidade pelos interrogados, com uma repercussão positiva associada a redução de estresse e melhoria da produtividade.

Na questão de contribuição ao estudo do uso da biofilia aplicado em ambientes hospitalares, levanta-se a análise dos resultados obtidos nessa abordagem como colaboração nos tópicos de trabalhos para futuros arquitetos, e na ampliação de repertório específico para essas edificações e público-alvo. Observa-se também a importância de uma revisão dos parâmetros de ocupação do solo que regem a taxa de permeabilidade e legislação que viabilizam a criação de espaços de descompressão, expostos para atender o contexto atual da sociedade.

O levantamento de maior número de dados complementares a essa investigação nesse com diferentes tipos de usuários e recintos pode ser visto como sugestão de uma pesquisa futura.

\section{AGRADECIMENTOS}

Agradecimento a instituição de saúde, a qual disponibilizou o espaço físico para a aplicação do questionário, sem a qual a realização desta pesquisa não teria sido possível. A disponibilidade e atenção do corpo de trabalhadores do hospital Adventista de Belém. A minha orientadora por acreditar nessa pesquisa.

\section{REFERÊNCIAS}

BELÉM (Município). Constituição (2008). Lei no 8655, de 30 de julho de 2008. Lei Complementar de Controle Urbanístico: Lei Complementar de Controle Urbanístico. Disponível em: <http://www.belem.pa. gov.br/segep/download/coletanea/PDF/n_urban_p/ Iccu.pdf>. Acesso em: 1 fev. 2020.

BONI, Felipe. Interiores Sustentáveis: Um guia prático para arquitetos e designers. E- book publicado pelo grupo UGreen- Escola Online de Construções Sustentáveis, 2018 p. 1. Disponível em: <https://www. ugreen.com.br/interiores-sustentaveis-guia/>. Acesso em: 31 jan. 2020.

CALABRESE, E.; KELLERT, S. The Practice of Biophilic Design. Disponível em: <https://www.researchgate.net/publication/321959928_The_Practice_of_ Biophilic_Design>. Acesso em: 1 abr. 2020.

COUTTS, C.; HAHN, M. Green Infrastructure,
Ecosystem Services, and Human Health. Int. J. Environ. Res. Public Health 2015, 12, 9768-9798. DOBBERT, Léa Yamaguchi. Áreas Verdes Hospitalares: Percepção e Conforto. Orientador: Prof. Dr. Demóstenes Ferreira Da Silva Filho. 2010. 122 p. Tese (Mestrado) - Universidade de São Paulo Escola de Agricultura "Luiz de Queiroz", Piracicaba, 2010. Disponível em: <https://teses.usp.br/teses/disponiveis/11/11150/tde-10022011-144702/publico/Lea_ Yamaguchi_Dobbert.pdf>. Acesso em: 31 jan. 2020.

GIL, A. C. Métodos e técnicas de pesquisa social - 6 . ed. - São Paulo: Atlas, 2008. Acesso em: 1 fev. 2020.

JOYE, Y. Architectural Lessons from Environmental Psychology: The Case of Biophilic Architecture. Review of General Psychology, v11, 1992. Disponível em: <https://pdfs.semanticscholar.org/08a9/bd25df650197fb58bf8b9c8647ad0abc07a7.pdf>. Acesso em: 31 jan. 2020.

LOURENÇO, Luis Fernando Amato et al. Metrópoles, cobertura vegetal, áreas verdes e saúde. Revista EstudosAvançadosvol.30no.86SãoPauloJan./Apr.2016. p.3. Disponível em: <http://www.scielo.br/scielo.php?script=sci_arttext\&pid=S0103-40142016000100113>. Acesso em: 31 jan. 2020.

LUKIANTCHUKI, Marieli Azoia; RAMOS, Katiúcia Megda. Edifícios Hospitalares: Contribuição da Arquitetura na Cura. IXEPCC - Encontro Internacional de Produção Científica UniCesumar, [s. I.], v. 9, p. 4-8, 2015. Disponível em: <http://www.cesumar.br/prppge/pesquisa/epcc2015/anais/katiucia_megda_ramos_1.pdf>. Acesso em: 1 fev. 2020.

MIYAZAKI, Y. Shinrin-yoku: A terapia japonesa dos banhos de floresta que melhora a sua saúde e bem-estar. Ed. Albatroz, 2018. Acesso em: 9 abr. 2020. PETENUZZO, Clovis. Coletivo 'Arquitetos Voluntários': constrói espaço para profissionais de saúde em hospital de Porto Alegre. Disponível em: <https://www.google.com.br/amp/s/casavogue.globo.com/amp/Arquitetura/noticia/2020/04/coletivo-arquitetos-voluntarios-constroi-espaco-para-profissionais-de-saude-em-hospital-de-porto-alegre.html >. Acesso em: 9 abr. 2020.

TEIXEIRA, Dimas Barbosa et al. Síndrome dos Edifícios Doentes em Recintos com Ventilação e Climatização Artificiais: Revisão de Literatura. Trabalho apresentado no $8^{\circ}$ Congresso Brasileiro de Defesa do Meio Ambiente, Rio de Janeiro, 2005. p.1 Disponível em: <http://repositorios.inmetro.gov.br/ handle/10926/347>. Acesso em: 9 abr. 2020. 


\section{AUTORES}

ORCID: http://orcid.org/0000-0003-2536-9237

STEPHANIE VENTURA SINELSON | Universidade Federal do Pará | Curso de especialização em conforto ambiental e sustentabilidade no espaço construído | Belém, PARÁ (PA) - Brasil | Correspondência para: Tv. Timbó, 1269 - Pedreira, Belém - PA, 66083049 |E-maill: stephventura.s@gmail.com

ORCID: http://orcid.org/0000-0001-8210-9082

MAGALI SANTOS MONASTERIOS MORALES, M.Sc. | Universidade Cidade de São Paulo | Construções Sustentáveis | São Paulo (SP) - Brasil | Correspondência para: Av Nova Independência 305 Brooklin SP / SP 04570-000 | E-maill: coach.megmorales@gmail.com

\section{COMO CITAR ESTE ARTIGO}

SINELSON, Stephanie Ventura; MORALES, Magali Santos Monasterios. Estudo Do Uso Da Biofília Em Ambientes Hospitalares Em Belém - PA. MIX Sustentável, [S.I.], v. 7, n. 1, p. 81-92, dez. 2020. ISSN 24473073. Disponível em:<http://www.nexos.ufsc. br/index.php/mixsustentavel $>$. Acesso em: dia mês. ano. doi:https://doi.org/10.29183/2447-3073.MIX2020. v7.n1.81-92. 
